\title{
Religiosidade e Enfrentamento em Contextos de Saúde e Doença: Revisão da Literatura
}

\author{
Juliana Bernardes de Faria ${ }^{7}$ \\ Eliane Maria Fleury Seidl \\ Universidade de Brasilia
}

\begin{abstract}
Resumo
No contexto das práticas de saúde, observa-se alusão freqüente à influência de aspectos religiosos na cura e no tratamento de enfermidades. Nessa perspectiva, a interface entre religiosidade e enfrentamento tem sido investigada, principalmente nas últimas duas décadas, em especial, por pesquisadores das ciências sociais e da saúde. Este artigo é uma revisão da literatura sobre religiosidade e enfrentamento no processo saúdedoença. O uso de estratégias cognitivas e/ou comportamentais para lidar com estressores, advindas da religiosidade da pessoa, é denominado enfrentamento religioso. São abordados aspectos históricos da associação entre religiosidade e saúde, as funções positivas e negativas do enfrentamento religioso, instrumentos de medida e avaliação do enfrentamento religioso e resultados de pesquisas na área. Palavras-chave: Religiosidade; enfrentamento; enfrentamento religioso; psicologia da saúde.
\end{abstract}

\section{Abstract}

\section{Religiosity and Coping in Health and Illness: A Review}

There are frequent allusions to the influence of religious aspects on cure and ilness processes in health contexts. In the last two decades, the relationship between religiosity and coping has been investigated mostly by social sciences and health researchers. This article consists on a literature review about religiosity and coping in health contexts. Cognitive or behavioral strategies which come from religiosity in order to cope with stress are called religious coping. This review includes historic aspects of the connection between religiosity and health, the positive and negative functions of religious coping, the religious coping assessment by instruments, and some research results in this area.

Keywords: Religiosity; coping; religious coping; health psychology.

Ao analisar o desenvolvimento da psicologia da religião, Emmons e Paloutzian (2003) constatam seu rápido crescimento nos últimos 15 anos. Destacam que, em alguns períodos da história da psicologia, o estudo dessa área ficou limitado devido a razões intradisciplinares, como o estabelecimento da psicologia científica e, conseqüentemente, a tendência de os psicólogos evitar tópicos difíceis de serem pesquisados mediante essa perspectiva metodológica. Os autores declaram, ainda, que o desafio para esses profissionais, no século atual, é o entendimento das bases psicológicas das crenças, experiências e comportamentos religiosos, com o propósito de ampliar tal conhecimento em prol do bem-estar do ser humano.

A necessidade da produção de conhecimento nessa área pode ser justificada pela relevância do tema religião nas sociedades humanas. Para ilustrar a relevância do tema nos dias atuais, pesquisas demográficas nacionais registram que aproximadamente $95 \%$ dos adultos nos Estados Unidos (Hoge, 1996) e 99\% dos adultos brasileiros (Klintowitz, 2001) declararam acreditar em Deus.

Apesar de os estudos em psicologia da religião interessarem a quase todas as áreas da psicologia, apenas a clínica e a psicologia da saúde começaram a incorporá-los em suas bases teóricas e práticas (Emmons \& Paloutzian, 2003). Nesses dois campos há, p. ex., grande número de investigações sobre as relações entre variáveis religiosas e enfrentamento de eventos estressores da vida (Harrison, Koenig, Hays, Eme-Akwari \& Pargament, 2001; Siegel, Anderman \& Schrimshaw, 2001). Este artigo tem por objetivo fazer uma revisão da literatura sobre o papel da religiosidade no enfrentamento em contextos de saúde e doença, apresentando alguns resultados de pesquisas contemporâneas sobre o tema. Pretende-se, assim, disponibilizar em língua

\footnotetext{
${ }^{1}$ Endereço para correspondência: SQN 203 Bloco D, 201, 70833 040, Brasilia, DF. E-mail: seidl@unb.br-jubfaria@hotmail.com/seidl@unb.br
}

portuguesa informações que possam contribuir para a produção de conhecimentos sobre psicologia e religiosidade, em especial nos diversos campos da atuação em saúde.

\section{Religiosidade e espiritualidade: Definições}

Definições de termos relacionados à religiosidade são complexas e numerosas, o que dificulta a realização de pesquisas sobre o tema. Alguns autores definem religiosidade como atributos relativos a uma religião específica, diferenciando-a de espiritualidade. Lukoff (1992), por exemplo, distingue religiosidade de espiritualidade, definindo a primeira como adesão a crenças e a práticas relativas a uma igreja ou instituição religiosa organizada, e a segunda como a relação estabelecida por uma pessoa com um ser ou uma força superior na qual ela acredita. De acordo com Spilka e McIntosh (1996, cf. citado em Siegel, Anderman \& Schrimshaw, 2001), a conceituação de religiosidade inclui aspectos individuais e institucionais, enquanto espiritualidade é um fenômeno apenas individual, identificado com aspectos como transcendência pessoal, sensibilidade 'extraconsciente' e fonte de sentidos para eventos na vida.

Worthington, Kurusu e McCullough (1996) definem uma pessoa religiosa como aquela que possui crenças religiosas e que valoriza, em alguma medida, a religião como instituição. Já uma pessoa espiritualizada é aquela que acredita, valoriza ou tem devoção a algum poder considerado superior, mas não necessariamente possui crenças religiosas ou é devoto de alguma religião institucionalizada.

Hill, Pargament, Wood, McCullogh e Swyers (2000) alertam, no entanto, que os termos religiosidade e espiritualidade não são incompatíveis e afirma que a tendência a polarizá-los não é frutífera para a pesquisa científica. Neste trabalho, optou-se por considerar apenas os termos relativos à religiosidade, como religião e religioso/a, abarcando tanto aspectos individuais como 
institucionais, conforme a proposição de estudiosos da área (Pargament, 1997; Tix \& Frazier, 1998).

\section{Religiosidade e saúde: Aspectos históricos}

Vários pesquisadores têm investigado a associação entre fatores relativos à religiosidade - práticas, afiliação, crenças - e saúde, tanto em sua dimensão física quanto mental. Essa associação possui raízes histórico-culturais muito antigas, presentes em mitos gregos, em rituais indígenas e nas inscrições bíblicas, que influenciaram e ainda vêm influenciando a cultura ocidental nos tempos atuais (Botelho, 1991). Segundo estudos antropológicos, a ignorância sobre as enfermidades contribuiu para que fosse iniciado, em determinado momento da história da humanidade, o processo de divinização do desconhecido. Em conseqüência, acreditava-se que os deuses tinham o poder de causar doenças e de curá-las. Além dos deuses, apenas aqueles que eram seus representantes na Terra podiam interferir no processo saúde-doença ou na vida-morte. Botelho (1991) cita, ainda, o uso de plantas alucinógenas como instrumentalização para facilitar a comunicação com seres sagrados e, dessa forma, possibilitar sua intervenção no curso da vida e da morte, muito presente em rituais de grupos indígenas de diversos continentes. Em relação ao Brasil, o autor faz referência a grupos religiosos como o Santo Daime, ritual religioso originado em tribos indígenas da Região Amazônica onde o chá da erva ayabuasca era tomado pelo pajé para aumentar seu poder de cura.

Levando em consideração a forte influência judaico-cristã na cultura ocidental, faz-se necessário analisar também alguns aspectos contidos na Bíblia. Botelho (1991) faz alusão ao surgimento do monoteísmo cristão, quando um Deus passou a ser o Senhor não só da vida e da morte, mas também da saúde e da doença, o que representava o Seu poder sobre os homens. Assim, como premiação pela obediência à lei divina era dada a saúde e, como castigo por seu descumprimento, a doença. Nos casos em que enfermidades acometiam pessoas obedientes e tementes a Ele, a figura do antideus ou Diabo era responsabilizada por isso. Dessa maneira, era explicada a incoerência do adoecimento de indivíduos que seguiam as regras divinas, culpando forças externas representadas pela figura demoníaca por esse adoecimento. Esta as faria adoecer apenas para mostrar que tinha força suficiente para influenciar situações, mesmo contrariando o que teria sido estabelecido por Deus. Encontra-se, freqüentemente, em relatos de pacientes de diversas religiões, alusão a causalidades religiosas de suas doenças assim como da cura desses males, ilustrada por falas como: Deus quis assim ou Se Deus quiser ficarei bom.

Ainda hoje, a interface entre saúde e religiosidade tem ocasionado modificações na medicina, em especial, na psiquiatria. De acordo com Jackson e Fulford (1997) há tempos discutem-se as semelhanças entre manifestações psicóticas e as de natureza religiosa/espiritual. Os autores defendem que a distinção desses dois fenômenos é de crucial importância, com implicações para os diagnósticos e tratamentos psiquiátricos propostos. São observadas, por exemplo, as modificações realizadas no Manual Diagnóstico e Estatístico de Transtornos Mentais (DSM - IV), da American Psychiatric AssociationAPA (1994), incluindo inovações na abordagem de temas culturais e religiosos ou espirituais. Nessa publicação, há uma seção intitulada Considerações éticas e culturais que apresenta orientações para melhor capacitar os profissionais médicos no uso do manual com pacientes oriundos de diferentes culturas. O propósito é evitar que variações de crenças, experiências ou comportamentos religiosos, típicos de determinado contexto sociocultural, sejam julgados como psicopatológicos, como, p. ex., alucinações auditivas ou visuais de conteúdo religioso, observadas em certos rituais.

Ainda com intuito de contribuir para a diferenciação entre enfermidades mentais e expressões da religiosidade, o Manual Diagnóstico e Estatístico de Transtornos Mentais (APA, 1994) apresenta nova categoria diagnóstica denominada Problema Religioso ou Espiritual (não considerada transtorno mental) e indica sua utilização:

quando o foco da atenção é um problema religioso ou espiritual, como por exemplo experiências aflitivas que envolvem perda ou questionamento de fé, problemas associados com conversão a uma nova fé, ou o questionamento de valores espirituais que podem não estar, necessariamente, ligados a uma igreja ou religião institucionalizada. (p. 693)

Nessa publicação, ressalta-se, também, a importância da religião como promotora de suporte emocional, instrumental e informativo. Constata-se, assim, a diversidade de implicações que a religiosidade pode ter nos fenômenos relacionados à saúde e ao adoecer. Neste trabalho, destacou-se, principalmente, seu papel no processo de enfrentamento.

\section{Enfrentamento: Conceituação}

O modelo teórico de estresse e enfrentamento denominado Modelo Interativo do Estresse define enfrentamento como "esforços cognitivos e comportamentais voltados para o manejo de exigências ou demandas internas ou externas, que são avaliadas como sobrecarga aos recursos pessoais" (Folkman, Lazarus, Gruen \& De Longis, 1986, p. 572). De acordo com esse modelo, a seleção das respostas de enfrentamento diante de situações estressantes sofre a mediação de avaliações cognitivas. $\mathrm{Na}$ avaliação primária, o indivíduo analisa se a situação é potencialmente desafiadora, prejudicial ou ameaçadora. $\mathrm{Na}$ secundária, o indivíduo examina seus recursos disponíveis para enfrentar a situação estressante, buscando alternativas mediante as quais a ameaça ou o dano pode ser contornada ou recompensas podem ser obtidas. As conclusões decorrentes dessas avaliações iniciais podem ser modificadas no transcorrer do processo.

Nesse modelo, classificam-se as respostas ou estratégias de enfrentamento de acordo com suas funções, destacando como modalidades principais: enfrentamento focalizado no problema e enfrentamento focalizado na emoção. O enfrentamento focalizado no problema caracteriza-se pelo manejo ou modificação da situação causadora de estresse, com o objetivo de controlar ou lidar com a ameaça, dano ou desafio. Representa estratégias ativas de aproximação em relação ao estressor, como, por exemplo, a solução de problemas. Por sua vez, o enfrentamento focalizado na emoção tem como função primordial regular a resposta emocional causada pela situação-problema com a qual a pessoa se depara, podendo apresentar atitudes de afastamento ou paliativas em relação à fonte 
de estresse, como negação ou esquiva. Demais estudos mostram ainda a utilização de outras estratégias, como busca de suporte social, busca de práticas religiosas e distração, na tentativa de lidar com os problemas (Seidl, Tróccoli \& Zannon, 2001; Vitalino, Russo, Carr, Maiuro \& Becker, 1985).

Antoniazzi, Dell'Aglio e Bandeira (1998), enfocando diversos modelos e estudos sobre o tema, afirmam que o enfrentamento tem sido estudado também em função de seus estilos, estratégias ou como processo. Os estilos estão mais relacionados a características de personalidade do indivíduo ou aos resultados do próprio enfrentamento, enquanto as estratégias referem-se a cognições ou a comportamentos direcionados a uma situação específica causadora de estresse. Na perspectiva de enfrentamento como processo, partese do princípio de que as respostas de enfrentamento apresentadas por uma pessoa podem mudar ao longo do tempo e de acordo com as exigências do contexto em que ocorre. Nessa concepção, uma pessoa pode apresentar diferentes estratégias de enfrentamento, em situações distintas (Lazarus \& Folkman, 1984).

Em coerência com a teoria de Lazarus e Folkman, Pargament (1997) defende a existência de alguns pressupostos do processo de enfrentamento. Assim, reafirma a importância de considerar que os eventos são interpretados pelas pessoas de acordo com os significados que têm para si. Dessa forma, o que torna uma experiência estressante não é o evento em si, mas as avaliações que as pessoas fazem da situação, o que leva à percepção do estressor como ameaça, dano ou desafio. Além disso, são analisados também os recursos disponíveis e responsabilidades ao lidar com a situação. Assinala ainda que as pessoas possuem um sistema de orientação que representa uma forma geral de compreender e lidar com as situações e que, em momentos de crise, o processo de enfrentamento é fortemente influenciado por esse sistema. $\mathrm{O}$ autor defende que as pessoas lidam com os problemas da forma que é possível em determinado momento, pois as opções de enfrentamento são limitadas pela pressão dos eventos, pelo sistema de crenças predominante e pelas avaliações dos recursos disponíveis para enfrentá-los.

Por fim, deve-se levar em consideração que o enfrentamento é influenciado pela cultura, já que ela pode modelar, p. ex., as avaliações da situação, o sistema de orientação das pessoas no mundo e as estratégias de enfrentamento que podem ser ensinadas e privilegiadas em um contexto sociocultural, em detrimento de outras. Vale ressaltar que grande parte da literatura sobre enfrentamento concentra-se em estudos do campo da psicologia da saúde, mais especificamente direcionada a condições de cronicidade e realização de procedimentos médicos (Pereira, 2002). Nesse sentido, Aldwin (1994) destaca a existência de sete tarefas adaptativas principais no manejo de enfermidades ou de agravos à saúde: lidar com conseqüências fisiológicas de doenças (dor, sintomas, incapacidade); lidar com o tratamento e o ambiente hospitalar; desenvolver e manter boas relações com a equipe de saúde; manter o equilibrio emocional; manter um senso de self, incluindo competência e controle; manter boas relações com familia e amigos; e preparar-se para futuras exigências. Essas tarefas podem ser identificadas com clareza no cotidiano da prática clínica do psicólogo que atua em saúde.

\section{Processo saúde-doença: Religiosidade e enfrentamento}

Observa-se que muitas pessoas atribuem a Deus o aparecimento ou a resolução dos problemas de saúde que as acometem e recorrem frequentemente a Ele como recurso cognitivo, emocional ou comportamental para enfrentá-los (Pargament, 1990). Nesse sentido, estratégias cognitivas ou comportamentais para lidar com eventos estressores, advindas da religião ou da espiritualidade da pessoa, foram definidas por Tix e Frazier (1998) como enfrentamento religioso (ER).

Harrison e cols. (2001) defendem a necessidade de estudo do ER pelo fato de que pessoas deparam-se com sofrimento, desafios e transições ao longo da vida, o que as impulsiona para além de suas próprias capacidades, levando-as a um processo dinâmico de enfrentamento no qual crenças e práticas religiosas podem estar inseridas. Nesse processo de enfrentamento, o indivíduo é visto como um agente proativo que lança mão de possibilidades e escolhas, norteando-se, no entanto, por um sistema de valores e de crenças preestabelecido. Dessa forma, ao revisar a literatura sobre prevalência de ER, Pargament (1997) conclui que nem todas as pessoas usam estratégias relativas à religiosidade em seu processo de enfrentamento, sendo mais propensas a utilizá-las aquelas cujas crenças e práticas religiosas são parte relevante de sua orientação geral no mundo.

Avaliando a literatura sobre significados e objetivos da religiosidade, Pargament e Park (1995), de forma inovadora em relação a posições de grandes teóricos como Freud e Marx, opõemse à pressuposição de que a religião teria a função apenas de proteger o indivíduo da confrontação com a realidade (por esquiva ou distorção de fatos reais). De acordo com os autores, há suporte empírico para funções diversas da religião, tais como alívio, conforto e consolo, busca de significado para problemas relevantes da existência (Ex.: injustiça), busca de intimidade (pela participação em rituais que favorecem a interação entre pessoas), busca da compreensão de si mesmo e busca pelo sagrado. Pargament e Park (1995) defendem ainda que a religião pode servir a diferentes propósitos de modo concomitante, pois as funções citadas anteriormente não são excludentes. Nessa perspectiva, a religiosidade passa a ser concebida como parte do processo de solução de problemas e não como estratégia defensiva ou de esquiva.

Em uma análise mais detalhada, Pargament e cols. (1988) argumentam que a religião pode assumir funções diferentes nos diversos estilos de solução de problemas que variam conforme a atribuição do lócus de responsabilidade e do nível de participação da pessoa na resolução do problema. O primeiro estilo é denominado autodirigido (self-directing) em que a responsabilidade pela resolução dos problemas é atribuída ao indivíduo, e Deus é concebido como dando liberdade à pessoa para conduzir sua própria vida. $\mathrm{O}$ segundo é o delegante (deferring), quando o indivíduo transfere tal responsabilidade a Deus, esperando que soluções venham por meio dos esforços Dele. O terceiro é o chamado estilo colaborativo (collaborative) no qual a responsabilidade é atribuída tanto ao indivíduo como a Deus, ambos percebidos como participantes ativos na solução de problemas.

Em estudo empírico, Pargament e cols. (1988) concluíram que a mesma pessoa pode lançar mão dos diversos estilos de solução de 
problemas em situações diferentes, o que parece influenciado pela competência pessoal percebida. Assim, pessoas que se percebem menos competentes seriam mais atraídas ao estilo delegante, devido ao suporte externo e à sensação de poder sobre o problema que esse estilo parece promover. Por sua vez, as pessoas que se percebem mais competentes tenderiam a utilizar o estilo autodirigido ou o colaborativo, em virtude de características como iniciativa pessoal e responsabilidade

Os autores apontam, ainda, que os estilos de solução de problemas podem inibir ou promover o desenvolvimento de competência pessoal e iniciativa. À guisa de exemplo, o delegante desencorajaria maior experimentação no mundo e oportunidades de aprendizado, enquanto os demais fariam o oposto. A aplicação desses conceitos no campo da saúde sugere que crenças religiosas podem, p. ex., favorecer a esquiva ou atrasar a busca de cuidados médicos ou modalidades de tratamento, nos casos em que o paciente designa todo o controle de sua doença a Deus (Chatters, 2000).

Além disso, Pargament, Smith, Koenig e Perez (1998) comentam que é difícil distinguir quando a religiosidade constitui ajuda ou obstáculo ao alcance de resultados adaptativos no processo de enfrentamento. Propõem, então, com base em investigação empírica, a existência de indicadores referentes à perda de integração da pessoa em relação a suas crenças, emoções, comportamentos, valores e sistema social que poderiam levar a um envolvimento ineficaz da religiosidade no enfrentamento.

Como exemplos desses indicadores ou sinais de alerta, temse a autonegação da pessoa em detrimento dos objetivos da igreja, o sentimento de que o estressor é uma punição de Deus e o conflito com o dogma da igreja ou grupo religioso do qual faz parte. É importante frisar que os autores não consideram esses sinais como indicadores de problemas em todos os casos, mas que seriam indícios da possível existência de dificuldades no envolvimento da religião no processo de enfrentamento, o que deve ser explorado mais atentamente. Nessa direção, sugere-se que os profissionais de saúde identifiquem no ER as potencialidades de ajuda, assim como de prejuízo.

Outro modelo importante para análise e intervenção clínica de psicólogos da saúde foi desenvolvido por Pargament e cols. (1998). Esse modelo identifica padrões positivos e negativos de enfrentamento religioso e examina suas implicações para a saúde. Nessa concepção, várias características do ER foram consideradas representativas do padrão positivo, como busca de apoio espiritual, perdão religioso, enfrentamento religioso colaborativo, ligação espiritual, purificação religiosa e redefinição benevolente do estressor. O padrão negativo foi caracterizado por descontentamento religioso, redefinição punitiva do estressor por Deus, presença de conflitos interpessoais com membros do grupo religioso, atribuição da causa do problema ao demônio e aparecimento de dúvida sobre os poderes de Deus para interferir na situação estressora. É importante notar que, segundo os autores, as pessoas podem usar os vários padrões combinados, com diferentes configurações de pensamentos, sentimentos e comportamentos referentes à religiosidade.
Pargament e cols. (1998) demonstraram ainda que esses padrões deER estavam relacionados a resultados diferentes do enfrentamento, principalmente no que tange à saúde mental. Assim, os padrões positivos associaram-se ao crescimento psicológico e espiritual, à avaliação positiva da qualidade de vida e à redução de sintomas sugestivos de problemas emocionais. Já o padrão negativo do ER correlacionou-se com sintomas de depressão. Com base nesses resultados, os autores concluíram que religiosidade pode representar tanto uma estratégia de enfrentamento adaptativa quanto um elemento estressor, chegando até mesmo a intensificar a gravidade do problema em foco.

Com o objetivo de fornecer explicações para resultados de pesquisas sobre religiosidade e saúde, Dull e Skokan (1995) desenvolveram um modelo teórico de base cognitiva. Um modelo semelhante também foi apresentado por Siegel e cols. (2001) em estudo sobre enfrentamento e religiosidade, também direcionado ao contexto da saúde. Ambos os modelos defendem a concepção de que crenças e práticas religiosas são mediadoras no processo saúdedoença, devido ao desenvolvimento de esquemas cognitivos que poderiam aumentar os recursos pessoais de enfrentamento - pelo incremento da sensação de controle e da auto-estima -, permitindo atribuir significado aos eventos estressores.

No âmbito da promoção da saúde e da prevenção de doenças, Dull e Skokan (1995) afirmam que as crenças religiosas tanto podem favorecer a adoção de comportamentos saudáveis (como redução do consumo de cafeína, de álcool e outras drogas), como a nãoadesão a práticas preventivas, devido ao desenvolvimento de um otimismo irrealista relativo à proteção (Ex.: crença de que nenhuma doença acometerá a pessoa, pois Deus a está protegendo). No caso de enfermidades instaladas, os autores defendem que crenças religiosas funcionam como mediadores cognitivos pela interpretação dos eventos adversos de maneira positiva, o que pode favorecer a adaptação e o ajustamento das pessoas à condição de saúde.

Em relação à auto-estima, a religiosidade parece fornecer padrões comparativos para a auto-avaliação e o autoconceito, de forma a valorizar a percepção que as pessoas têm de si mesmas. Pode desempenhar ainda papel importante no modo como as pessoas percebem os eventos, seja de forma otimista, seja de forma pessimista, através da mediação no processo de avaliação deles (Dull \& Skokan, 1995). Além disso, esses autores afirmam que a religiosidade permite à pessoa atribuir significados aos eventos, compreendendo-os como parte de um propósito ou projeto mais amplo, mediante a crença de que nada ocorre ao acaso e de que acontecimentos da vida são determinados por uma força superior. Possibilitam, ainda, a crença de que tais eventos podem levar a um crescimento pessoal, como sabedoria, equilibrio e maturidade.

Esses autores fazem referência ainda à conexão corpo-mente explicitada em pesquisas de psiconeuroimunologia, campo interdisciplinar que estuda as relações entre os sistemas nervoso e imunológico. Ao analisar esses dados, verifica-se que as cognições podem mediar estados fisiológicos, influenciando a efetividade imunológica e, direta ou indiretamente, a saúde. Dados de revisão bibliográfica, em que se analisam as contribuições dessa área de pesquisa entre 1939 e 2001, corroboram essa idéia ao concluir que a 
modulação imunológica produzida por estressores ou por intervenções psicossociais pode conduzir a mudanças de saúde, com evidências diretas em casos de doenças infecciosas (Kiecolt-Glaser, McGuire, Robles \& Glaser, 2002). Nesse sentido, a religiosidade compreendida como parte do sistema de cognições do indivíduo, poderia estar afetando a saúde por intermédio dessa interface psiconeuroimunológica. Essa seria uma das possíveis hipóteses explicativas, nessa abordagem, das influências positivas das crenças religiosas nos estados de saúde, em especial, em enfermidades diretamente relacionadas ao sistema imunológico.

Por fim, Siegel e cols. (2001) destacam o papel da religião na facilitação do acesso a redes de suporte e de integração social nas instituições religiosas e suas congregações. Complementarmente, Ellison (1994) observa que pessoas costumam recorrer a instituições religiosas em tempos de doenças severas, pelo fato destas estarem historicamente identificadas com a oferta de apoio emocional, prática assistencial e caridade aos enfermos e necessitados.

\section{Medida e avaliação do enfrentamento religioso}

Tendo por base os aspectos apresentados anteriormente, evidencia-se a necessidade do aprimoramento da avaliação do ER de forma a propiciar o desenvolvimento de estudos na área e fomentar intervenções que se mostrem necessárias. De acordo com Harrison e cols. (2001), os métodos de análise do ER devem levar em conta sua multidimensionalidade, incluindo as mediações cognitivas relacionadas ao evento em foco, os resultados esperados e as estratégias usadas para atingir esses resultados. Ao avaliar os instrumentos de avaliação de ER existentes, Siegel e cols. (2001) assinalam que a inconsistência entre muitos dos resultados de pesquisas deve-se às diferenças de conceituação e de operacionalização das medidas.

Historicamente, diferentes abordagens têm sido desenvolvidas para avaliação e mensuração do ER (Pargament, 1999):

1. levantamento de dados sobre práticas religiosas (Ex.: freqüência de participação em cultos religiosos e orações);

2. avaliação com base em medida única (Ex.: questão ou item referente ao envolvimento da religiosidade no enfrentamento de um evento específico);

3. inclusão de um ou mais itens específicos sobre crenças e/ou práticas religiosas em escalas de enfrentamento que mensuram tanto estratégias religiosas quanto não religiosas;

4. emprego de instrumentos psicométricos que medem a utilização e freqüência de estratégias específicas de ER; e,

5. uso de medidas de ER mais parcimoniosas, como a exploração dos padrões positivo e negativo, conforme descritos por Pargament (1998).

A seguir são apresentadas descrições de dois instrumentos de medida de ER: RCOPE e Brief RCOPE.

\section{RCOPE e BriefRCOPE}

Esses dois instrumentos de medida de ER foram escolhidos para análise mais detalhada por caracterizarem instrumentos que vêm sendo utilizados atualmente em estudos científicos e por possuírem base teórica coerente com enfoques reconhecidos na área, como o modelo de estresse e enfrentamento de Lazarus e Folkman.

Pargament e sua equipe desenvolveram essas medidas de ER mediante o estudo de amostras de pessoas em processo de enfrentamento diante de estressores diversos. Essas medidas têm se mostrado mais válidas do que as excessivamente gerais tradicionalmente usadas que avaliam o ER em uma concepção muito genérica, em detrimento de fatores ou dimensões (Pargament, Tarakeshwar, Ellison \& Wulff, 2001).

O desenvolvimento e a validação do RCOPE, segundo Pargament, Koenig e Perez (2000), permitiu melhor compreensão dos papéis da religião no processo de enfrentamento, o que tem possibilitado maior integração de temas religiosos em procedimentos de avaliação psicológica, aconselhamento e atividades como a capacitação de profissionais da área de saúde. Como pressupostos norteadores do processo de desenvolvimento do instrumento, os autores mencionaram o embasamento teórico, a visão funcional da religião e dos papéis que ela desempenha no processo de enfrentamento, pois consideram mais importante compreender como os indivíduos fazem uso da religião no lidar com eventos estressores de suas vidas do que apenas descrever suas práticas religiosas. Com base nessas informações, fundamentaram a construção do RCOPE nas principais funções da religiosidade, de acordo com as concepções de teóricos da filosofia, da psicologia e da antropologia, como Geertz, Fromm, Freud e Durkheim. Para esse propósito, Pargament e cols. (2000) enfatizaram cinco funções: produção de significado, controle de situações, disponibilidade de conforto, intimidade e integração social, e transformação da vida. Nessa escala, considera-se também o lado negativo da religiosidade, pois os autores assinalam a importância de se identificar formas potencialmente disfuncionais do ER.

O último pressuposto refere-se ao fato de ser um instrumento construído com base empírica, já que decorre da combinação de itens derivados da teoria e de dados clínicos (Ex.: descrição sobre como as pessoas lidam com estressores). Trata-se, portanto, de uma medida abrangente, visto que o ER tem um caráter multidimensional.

Os pesquisadores salientam, ainda, que seria impossível desenvolver escalas que refletissem a totalidade das estratégias de ER utilizadas por diferentes grupos de pessoas em situações diversas. Enfatizam, então, que a aplicabilidade do RCOPE refere-se, principalmente, a pessoas de cultura norte-americana e com tradições religiosas judaico-cristãs, em detrimento de religiões orientais. Os resultados da validação demonstraram, no entanto, que o RCOPE é aplicável a populações com níveis diferentes de envolvimento religioso e no enfrentamento de problemas diversos.

No RCOPE, há 100 itens divididos em 17 subescalas. O participante deve assinalar um número da escala de respostas para indicar o quanto fez uso da modalidade de enfrentamento religioso descrita em cada item, em determinada situação $(0=$ nunca; $2=$ um

${ }^{2}$ Este instrumento foi adaptado para o português e analisado quanto à estrutura fatorial com amostra de pessoas HIV positivas na Dissertação de Mestrado defendida pela primeira autora (Faria, 2004), junto ao Instituto de Psicologia da Universidade de Brasília, sob orientação da segunda autora. 
pouco; 3=algumas vezes; 4=quase sempre). Cada subescala referese a um fator do instrumento, apresentando consistência interna alpha de Cronbach - com variação de 0,61 a 0,94 (Pargament \& cols. 2000).

Como esse instrumento é considerado longo, foi desenvolvida uma versão breve denominada BriefRCOPE ${ }^{2}$ que possibilita uma análise menos detalhada das características do ER, mas apresenta maior praticidade em sua utilização (Pargament \& cols., 2001). Partindo da hipótese de que a maioria dos fatores e itens do RCOPE poderia ser classificada em enfrentamento positivo ou negativo, uma análise fatorial exploratória foi realizada para gerar apenas dois fatores (Pargament \& cols., 1998). Assim, essa solução fatorial permitiu a elaboração da versão breve, composta de sete itens de ER positivo e sete de ER negativo. O ER do padrão positivo pode ser definido, tendo por base a análise das categorias e respectivos itens que as compõem, como modalidade de enfrentamento baseada na religiosidade como fonte de amor, cuidado, força, ajuda, purificação e ressignificação positiva do estressor. Em contrapartida, o ER negativo pode ser definido como modalidade de enfrentamento baseada na religiosidade como fonte de conflito intra e/ou interpessoal, sentimentos de culpa e punição, insegurança e ressignificação negativa do estressor.

A consistência interna encontrada para o padrão positivo de ER foi 0,87 (em amostra de pacientes hospitalizados) e 0,90 (em amostra de estudantes universitários). Para o padrão negativo foram encontrados 0,69 e 0,81 nessas mesmas amostras, respectivamente. Nos resultados da validação do BriefRCOPE, verifica-se que as duas subescalas - ER positivo e negativo - exibem padrões distintos de correlação com outras medidas. $\mathrm{O}$ uso do padrão positivo de ER, p. ex., correlacionou-se com níveis reduzidos de sintomatologia psicossomática, enquanto o enfrentamento religioso de padrão negativo esteve correlacionado à saúde física precária, níveis altos de sofrimento emocional e de sintomatologia psicossomática (Pargament \& cols., 2000).

\section{Resultados de pesquisas sobre enfrentamento religioso}

Ao avaliar estudos sobre a prevalência do ER, Pargament (1997) observou que os resultados variaram conforme as características das amostras e o tipo de evento estressor estudado. Ademais, analisando-se os dados verificou-se que um percentual elevado de pessoas, com diferentes condições de saúde, fazia uso desse tipo de enfrentamento. Em amostras de pacientes hospitalizados, a prevalência variou de 73,4\% a 86\% (Ayale, Mulligan, Gheorghiu \& Reyes-Ortiz, 1999; King, Speck \& Thomas, 1999; Koenig, 1998). Em amostras de pacientes em tratamento ambulatorial, tal prevalência foi de aproximadamente 60\% de utilização do ER (Kirov, Kemp, Kirov \& David, 1998; Koenig, Weiner, Peterson, Meador \& Keefe, 1997).

Em revisão de literatura com o objetivo de resumir e avaliar resultados recentes de pesquisas sobre ER, Harrison e cols. (2001) verificaram que há evidências recentes das relações entre ER e uma ampla variedade de medidas de adaptação psicológica. Assim, sintomas de ansiedade associaram-se significativamente com estratégias de ER negativo e com religiosidade extrínseca, aquela em que a religião é utilizada como meio para atingir um objetivo ou para obter algo específico (Ex.: rezar/orar com o objetivo de ser curado de uma doença). Com base nos resultados verifica-se ainda que auto-estima, satisfação com a vida e percepção positiva da qualidade de vida têm sido associadas ao padrão positivo e à religiosidade intrínseca cujo foco é a crença religiosa propriamente dita, independente do interesse na obtenção de ganhos secundários.

Em outro estudo de revisão bibliográfica sobre uso da religiosidade em contextos de saúde e doença, Siegel e cols. (2001) afirmaram que a associação entre variáveis religiosas e ajustamento psicológico tem sido pesquisada com maior freqüência entre pacientes com câncer e idosos hospitalizados ou cronicamente doentes. Em relação aos estudos com idosos, os resultados indicaram associação de religiosidade com, por exemplo, percepção positiva da eficácia do enfrentamento e índices mais elevados de suporte social e de qualidade de vida. Além disso, variáveis religiosas estiveram associadas a menores índices de depressão e ansiedade. Afirmaram, ainda, que há evidências de que idosos têm mais propensão a empregar religião como recurso de enfrentamento.

Em consonância, Pargament e cols. (2000), fazendo referência a outras fontes de dados, destacaram que, quando interrogadas sobre como lidam ou enfrentam as situações mais estressantes, muitas pessoas fazem menção à religião, em particular, os idosos, minorias étnicas e aquelas em crise de ameaça à vida, ressaltando que essa estratégia é mais citada do que qualquer outra modalidade de enfrentamento. Outra variável mencionada como fator que influencia o uso da religiosidade para lidar com problemas é o tipo de religião e suas crenças específicas. De acordo com resultados encontrados por Tix e Frazier (1998), ER esteve associado a um melhor ajustamento psicológico entre pessoas afetadas por estressores em geral, mas sua utilização parece ter sido mais eficaz para protestantes (também denominados evangélicos) do que para católicos na diminuição de angústia e na promoção de satisfação com a vida.

Nessa linha de análise, Ferraro e Albrecht-Jensen (1991) examinaram a associação entre medidas de afiliação religiosa e percepção do estado de saúde, com base na auto-avaliação do respondente, em amostra de adultos da população norteamericana em geral. Analisando os resultados, verificou-se que pessoas mais idosas relataram maiores níveis de religiosidade; constataram, ainda, que idade e renda familiar foram as características pessoais que apresentaram maiores efeitos sobre a percepção do estado de saúde.

Segundo Ellison (1991), há na literatura registros de que a religiosidade pode influenciar vários aspectos do bem-estar subjetivo (BES) por favorecer a integração e o suporte social, o estabelecimento de relações com o divino, a promoção de sistemas de significado e de coerência existencial ou mesmo por estimular estilos de vida específicos de algumas religiões. As relações com o divino podem ser caracterizadas por relações sociais imaginárias com seres provenientes de crenças religiosas, como, por exemplo, Deus, Jesus Cristo, santos, anjos e entidades espirituais. Pollner (1989) defende que as pessoas podem construir relações com o divino tanto quanto constróem relações 
sociais, engajando o ser divino como fonte de consolo e de orientação. Sugere ainda que essa relação pode melhorar o BES percebido por propiciar senso de ordenamento e previsibilidade dos eventos e novos significados para situações problemáticas (Ex.: eventos adversos de vida podem ser vistos como oportunidades de crescimento espiritual).

Estudos têm sido realizados nos últimos anos, investigando relações entre BES, enfrentamento e religiosidade. Um estudo empírico no contexto da saúde relacionando especificamente enfrentamento religioso e BES foi realizado por Rammohan, Rao e Subbakrishna (2002), em um hospital público da Índia, com 60 cuidadores, parentes de pacientes portadores de esquizofrenia, predominantemente de nível socioeconômico baixo. Nessa amostra, 23\% atribuíram inicialmente à doença causas religiosas (Ex.: espíritos malignos), 33\% citaram a procura por métodos religiosos de tratamento antes de aderir à farmacologia e 30\% afirmaram que participar de rituais religiosos fortaleceu a crença de que Deus controla as situações e os orienta em relação a elas. Com base nos resultados, ficou evidenciado, no entanto, que idade, educação e gênero dos cuidadores estiveram significativamente correlacionados a BES; assim, pessoas mais jovens, com nível educacional mais elevado e do sexo masculino obtiveram maiores escores nessa variável. Outro dado relevante é que o emprego de estratégias de enfrentamento de negação e de solução de problemas foi preditor significativo de BES nesse grupo, na medida em que ao uso de menos estratégias de negação e mais recursos para a solução de problemas associaram-se escores mais altos de BES. Além disso, a força da fé religiosa - considerada neste estudo como um componente cognitivo do enfrentamento religioso - emergiu como preditor do $\mathrm{BES}$, o que não aconteceu com práticas religiosas, o componente comportamental do enfrentamento religioso.

Estudos têm sido realizados enfocando o tema religiosidade em amostras de pessoas vivendo em condições específicas de saúde, como com HIV/AIDS. Siegel e Schrimshaw (2002) realizaram pesquisa com adultos norte-americanos soropositivos investigando os benefícios percebidos por eles na utilização do enfrentamento religioso. Os participantes relataram uma variedade de benefícios provenientes de suas crenças e práticas dessa natureza, incluindo: 1) favorecimento de emoções e sentimentos de conforto; 2) sensação de força, poder e controle; 3) diminuição da carga emocional da doença; 4) disponibilidade de suporte social e senso de pertencimento; 5) apoio espiritual mediante uma relação com Deus; 6) facilitação da aceitação da doença; 7) auxilio na preservação da saúde; 8) alívio do medo e da incerteza perante a morte; e, 9) maior facilidade de autoaceitação e redução da culpa autodirigida. Esses aspectos, segundo os autores, sugerem mecanismos potenciais de como a religiosidade pode afetar a adaptação psicológica em contextos de ameaça à saúde.

Estudo brasileiro realizado por Faria \& Seidl (no prelo) investigou a relação entre religiosidade, enfrentamento e BES junto a pessoas vivendo com HIV/AIDS, cujo objetivo foi analisar o poder de predição de diferentes modalidades de enfrentamento, incluindo o $\mathrm{ER}$, da escolaridade e da condição de saúde sobre o componente afetivo do BES. A amostra foi composta de 110 adultos soropositivos em acompanhamento médico ambulatorial. A quase totalidade da amostra relatou ter crenças religiosas e $90 \%$ referiram acreditar que a religiosidade poderia ajudá-los a lidar com problemas de saúde. No que concerne ao ER, observou-se uso freqüente pela maioria da amostra, com predomínio do padrão positivo de ER, caracterizado pela busca de amor, cuidado, ajuda, força e orientação por meio da religiosidade, indicador de modos mais adaptativos para lidar com o problema. O padrão positivo de ER esteve associado ainda à freqüência elevada de práticas religiosas em geral, públicas e privadas. Os participantes que utilizavam mais enfrentamento focalizado no problema e ER positivo e menos estratégias de enfrentamento focalizadas na emoção apresentaram escores mais elevados de afeto positivo, caracterizado por sentimentos como alegria, exaltação, contentamento e felicidade. Não foi observada influência significativa das práticas religiosas públicas e privadas e dos tipos de religião sobre o componente afetivo do BES

Contudo, nem todos os resultados apontam para efeitos positivos do ER, como discutido anteriormente. Jenkins (1995) apresentou resultados que ressaltam controvérsias sobre as influências da religiosidade no manejo da AIDS, num momento histórico em que ainda não havia tratamento eficaz para essa enfermidade. Um grupo de 422 pessoas soropositivas, $93 \%$ do sexo masculino, membros de instituições militares e residentes nos EUA, respondeu a questionários com o objetivo de investigar o enfrentamento religioso. Em relação aos estilos de enfrentamento descritos por Pargament e cols. (1988), observou-se que $41 \%$ dos participantes utilizaram predominantemente o estilo autodirigido, $42 \%$ o delegante e $18 \%$ o colaborativo. Entre os que utilizavam mais o estilo delegante, predominaram indivíduos em estágios mais avançados da doença. Isso poderia levar a atitudes de cuidados à saúde menos ativas, já que, de acordo com a definição desse estilo de enfrentamento, a cura da doença é atribuída a Deus, sendo transferido o lócus de responsabilidade para Ele.

Cabe ressaltar que as diferenças e controvérsias encontradas nos resultados de pesquisas, nessa área, segundo Ferraro e Albrecht-Jensen (1991), podem ser conseqüência do uso de diferentes conceituações e medidas, como comentado anteriormente, mas também pelo fato de religiosidade ser um fenômeno multidimensional, podendo algumas de suas dimensões apresentar efeitos positivos sobre a saúde e o bem-estar, e outras não.

\section{Considerações Finais}

Um dos objetivos deste artigo foi trazer informações e estimular reflexões sobre o papel da religiosidade no enfrentamento em contextos de saúde e doença. O panorama atual dos estudos sobre religiosidade e saúde demonstra, às vezes, uma valorização apenas de seus aspectos adaptativos. Contudo, estudiosos alertam para possíveis efeitos, tanto positivos como negativos, da religiosidade no enfrentamento, o que pode ser influenciado pelos modos de lidar com eventos estressores e pelas crenças e práticas religiosas envolvidas no processo de enfrentamento. Pautando-se nas contribuições de Pargament (1997) acerca do papel do ER, ressalta-se que um problema muitas vezes encontrado não é a proposição de explicação religiosa para os eventos adversos que ocorrem na vida, mas sim o uso exclusivo dessas explicações em detrimento de outras. Esse pesquisador sugere que sejam 
disponibilizadas aos pacientes outras possíveis explicações para os fenômenos que acometem sua saúde, de natureza distinta da religiosa, como as médico-científicas.

É importante ressaltar que, ainda segundo Pargament (1997), o uso de enfrentamento religioso só faz sentido se essas crenças fizerem parte do sistema de valores geral da pessoa. Dessa forma, não se trata aqui de uma defesa do uso da religiosidade no enfrentamento como instrumento, mas sim de sua valorização e incentivo quando o paciente possui crenças religiosas e, em virtude disso, já o faz em sua vida. Ademais, em estudo sobre aids, psicologia e religião, Paiva (1998) ressalta que o envolvimento da religiosidade no enfrentamento não pode ser direcionado unicamente à cura da doença, mas ao bem-estar mais amplo da pessoa, incluindo outros aspectos da vida.

Estudos sobre o tema têm implicações para a prática de profissionais da saúde, em especial, psicólogos. Nesse sentido, sugerese propiciar a escuta de conflitos psicológicos de origem religiosa, assim como se faz com demais aspectos da vida, de forma a possibilitar acolhimento e, quando necessário, a ressignificação dos mesmos. A religiosidade é parte relevante da vida de muitas pessoas e não pode ser negligenciada no contexto do atendimento psicológico.

A relevância do tema deve-se, também, às relações entre crenças religiosas e atuação em psicologia, presentes desde o período da formação acadêmica de muitos desses profissionais, representando conflitos em alguns casos, como demonstrado por Freitas (2002) em seu estudo sobre crença religiosa e personalidade em estudantes de psicologia. Aspectos éticos e pessoais podem estar envolvidos na dificuldade dos psicólogos em abordar a religiosidade em seus atendimentos ou no contexto psicoterapêutico, configurando temas que necessitam ser inseridos na agenda de estudos e debates desses profissionais em seu processo de formação e qualificação. Ressaltase, também, o imperativo de realizar mais pesquisas que investiguem a interface entre religiosidade e saúde na população brasileira, cujas características culturais englobam aspectos religiosos muito particulares, o que pode levar a resultados diferenciados dos encontrados em outras culturas.

\section{Referências}

Aldwin, C. M. (1994). Stress, coping and development: An integrative perspective. London: The Gilford.

American Psychiatric Association (1994). Manual Diagnóstico e Estatístico de Transtornos Mentais ( $4^{a}$ ed.). Porto Alegre: Artmed.

Antoniazzi, A. S., Dell'Aglio, D. D. \& Bandeira, D. R. (1998). O conceito de coping. Uma revisão teórica. Estudos de Psicologia (Natal), 3, 1-15.

Ayale, H., Mullingan, T., Gheorghiu, S. \& Reyes-Ortiz, C. (1999). Religious activity improves life satisfaction for some physicians and older patients. Journal of the American Geriatrics Society, 47, 453-455.

Botelho, J. B. (1991). Medicina e religião: conflito de competências. Manaus: Metro Cúbico.

Chatters, L. (2000). Religion and health: public health research and practice. Annual Review of Public Health, 21, 335-367.

Dull, V. T. \& Skokan, L. A. (1995). A cognitive model of religion's influence on health. Journal of Social Issues, 51, 49-64.

Ellison, C. G. (1991). Religious involvement and subjective well-being. Journal for Health and Social Behavior, 32, 80-99.
Ellison, C. G. (1994). Religion, the life stress paradigm, and the study of depression. Em J. S. Levin (Org.), Religion in aging and health (pp. 78-121). Thousand Oaks, CA: Sage.

Emmons, R. A. \& Paloutzian, R. F. (2003). The psychology of religion. Annual Reviews Psychology, 54, 377-402.

Faria, J. B. (2004). Religiosidade, enfrentamento e bem-estar subjetivo em pessoas vivendo com HIV / AIDS. Dissertação de Mestrado não-publicada, Instituto de Psicologia, Universidade de Brasília. Brasília, DF.

Faria, J. B. \& Seidl, E. M. (no prelo). Religiosidade, enfrentamento e bem-estar subjetivo em pessoas vivendo com HIV/Aids. Psicologia em Estudo.

Ferraro, K. F. \& Albrecht-Jensen, C. M. (1991). Does religion influence adult health? The Journal for the Scientific Study of Religion, 30, 193-202.

Folkman, S., Lazarus, R. S., Gruen, R. J. \& De Longis, A. (1986). Appraisal, coping, health status and psychological symptoms. Journal of Personality and Social Psychology, 50, 571-579.

Freitas, M. H. (2002). Crença religiosa e personalidade em estudantes de psicologia: Um estudo por meio do Questionário Pratte do método de Rorschach. Tese de Doutorado não-publicada, Instituto de Psicologia, Universidade de Brasília. Brasília, DF.

Harrison, M. O., Koenig, H. G., Hays, J. C., Eme-Akwari, A. G. \& Pargament, K. I. (2001). The epidemiology of religious coping: a review of recent literature. International Review of Psychiatry, 13, 86-93.

Hill, P. C., Pargament, K. I., Wood, R. W. Jr., McCullough, M. E. \& Swyers, J. P. (2000). Conceptualizing religion and spirituality: points of commonality, points of departure. Journal of Theory of Society of Behaviorism, 30, 51-77.

Hoge, D. R. (1996). Religion in America: the demographics of belief and affiliation. Em E. P. Shafranske (Org.), Religion and the clinical practice of psychology (pp. 2141). Washington: APA.

Jackson, M. \& Fulford, K. W. M. (1997). Spiritual experience and psychopatology. Phylosophy, Psychiatry, and Psychology, 4, 42-65.

Jenkins, R. A. (1995). Religion and HIV: Implications for research and intervention. Journal of Social Issues, 51, 131-144.

Kiecolt-Glaser, J. K., McGuire, L., Robles, T. F. \& Glaser, R. (2002). Psychoneuroimmunology and psychosomatic medicine: back to the future. American Psychosomatic Society, 64, 15-28.

King, M., Speck, P. \& Thomas, A. (1999). The effect of spiritual beliefs on outcome from illness. Social Science \& Medicine, 48, 1291-1299.

Kirov, G., Kemp, R., Kirov, K. \& David, A. S. (1998). Religious faith after psychotic illness. Psychopatology, 31, 234-45.

Klintowitz, J. (2001). Um povo que acredita. Veja, 19 de dezembro, 124-133.

Koenig, H. G. (1998). Religious attitudes and practices of hospitalized medically ill older adults. International Journal of Geriatric Psychiatry, 13, 213-224.

Koenig, H. G., Weiner, D. K., Peterson, B. L., Meador, K. G., Keefe, F. J. (1997). Religious coping in the nursing home: Biopsychosocial model. International Journal of Psychiatry in Medicine, 27, 365-76.

Lazarus, R. S. \& Folkman, S. (1984). Stress, appraisal, and coping. New York: Springer.

Lukoff, D. (1992). Toward a more culturally sensitive DSM-IV (psychoreligious and psychospiritual problems). The Journal of Nervous and Mental Disease, 180, 673-682.

Paiva, G. J. (1998). AIDS, psicologia e religião: O estado da questão na literatura psicológica. Psicologia: Teoria e Pesquisa, 14, 27-34.

Pargament, K. I. (1990). God help me: Toward a theoretical framework of coping for the psychology of religion. Research in the Social Scientific Study of Religion, 2, 195-224.

Pargament, K. I. (1997). The psychology of religion and coping: Theory, research, practice. New York, USA: The Guilford.

Pargament, K.I. (1999). Religious/spiritual coping. Em Fetzer Institute/National Institute on Aging Working Group (Orgs.), Multidimensional measurement of religiousness/spirituality for use in bealth research (pp. 43-56). Kalamazoo, MI: Fetzer Institute.

Pargament, K. I., Kennell, J., Hathaway, W., Grevengoed, N., Newman, J. \& Jones, W. (1988). Religion and the problem-solving process: three styles of coping. Journal for the Scientific Study of Religion, 27, 90-104. 
Pargament, K. I., Koenig, H. G. \& Perez, L. M. (2000). The many methods of religious coping: development and initial validation of the RCOPE. Journal of Clinical Psychology, 56, 519-543.

Pargament, K. I. \& Park, C. L. (1995). Merely a defense? The variety of religious means and ends. Journal of Social Issues, 51, 13-32.

Pargament, K. I., Smith, B. W., Koenig, H. G. \& Perez, L. (1998). Patterns of positive and negative religious coping with major life stressors. Journal for the Scientific Study of Religion, 1, 710-724.

Pargament, K. I., Tarakeshwar, N., Ellison, C. G. \& Wulff, K. M. (2001). Religious coping among the religious: the relationships between religious coping and well-being in a national sample of Presbyterian clergy, elders, and members. Journal for the Scientific Study of Religion, 40, 491-513.

Pereira, M. E. S. M. (2002). Aspectos psicológicos da reabilitação em traumatismo raquimedular: modalidades de enfrentamento do paciente e seu familiar/acompanbante. Dissertação de Mestrado não-publicada, Instituto de Psicologia, Universidade de Brasília. Brasilia, DF.

Pollner, M. (1989). Divine relations, social relations, and well-being. Journal for Health and Social Behavior, 30, 92-104.

Rammohan, A., Rao, K. \& Subbakrishna, D. K. (2002). Religious coping and psychological wellbeing in careers of relatives with schizophrenia. Acta Psychiatrica Scandinavica, 105, 356-362.
Seidl, E. M. F., Tróccoli, B. T. \& Zannon, C. M. L. C. (2001). Análise fatorial de uma medida de estratégias de enfrentamento. Psicologia: Teoria e Pesquisa, 17, 225 234

Siegel, K., Anderman, S. J. \& Schrismshaw, E. W. (2001). Religion and coping with health-related stress. Psychology and Health, 16, 631-653.

Siegel, K. \& Schrimshaw, E. W. (2002). The perceived benefits of religious and spiritual coping among older adults living with HIV/AIDS. Journal for the Scientific Study of Religion, 41, 91-102.

Tix, A. P. \& Frazier, P. A. (1998). The use of religious coping during stressful life events: Main effects, moderation, and mediation. Journal for Consulting \& Clinical Psychology, 66, 411-22.

Vitalino, P. P., Russo, J., Carr, J. E., Maiuro, R. D. \& Becker, J. (1985). The ways of coping checklist: Revision and psychometric properties. Multivariate Behavioral Research, 20, 3-26.

Worthington Jr., E. L., Kurusu, T. A. \& McCullough, M. E. (1996). Empirical research on psychotherapeutic processes and outcomes: A 10-year review and research prospectus. Psychological Bulletin, 119, 448-487.

Recebido: 08/11/2003

$1^{a}$ revisão: $30 / 07 / 2004$

Aceite final: 23/09/2004

Sobre as autoras

Juliana Bernardes de Faria é Psicóloga, Mestre em Psicologia pela Universidade de Brasília (UnB), Pesquisadora do Programa Nacional de DST e AIDS junto ao Centro de Estudos Pesquisas e Informações do Ministério da Saúde.

Eliane Maria Fleury Seidl é Psicóloga, Doutora em Psicologia pela Universidade de Brasília (UnB), professora adjunta do Instituto de Psicologia da UnB. Coordenadora de projeto de extensão de ação contínua denominado Projeto Com-Vivência (Ações Integradas de Estudos e Atendimento a Pessoas Portadoras de HIV/Aids e Familiares), no Hospital Universitário de Brasília. 